\title{
Towards the development of an automated electrical self-potential sensor of melt and rainwater flow in snow
}

\section{Article}

Cite this article: Priestley A, Kulessa B, Essery R, Lejeune Y, Le Gac E, Blackford J (2022). Towards the development of an automated electrical self-potential sensor of melt and rainwater flow in snow. Journal of Glaciology 68(270), 720-732. https://doi.org/10.1017/ jog.2021.128

\section{Received: 29 April 2021}

Revised: 11 November 2021

Accepted: 12 November 2021

First published online: 20 December 2021

\section{Keywords:}

Glacier geophysics; glaciological instruments and methods; snow

\section{Author for correspondence:}

Alex Priestley;

E-mail: alex.priestley@ed.ac.uk (c) The Author(s), 2021. Published by Cambridge University Press. This is an Open Access article, distributed under the terms of the Creative Commons Attribution licence (https://creativecommons.org/licenses/by/4.0/), which permits unrestricted re-use, distribution, and reproduction in any medium, provided the original work is properly cited.

\section{Alex Priestley ${ }^{1}$ (D), Bernd Kulessa ${ }^{2,3}$, Richard Essery ${ }^{1}$, Yves Lejeune ${ }^{4}$, Erwan Le $\mathrm{Gac}^{4}$ and Jane Blackford ${ }^{5}$}

\begin{abstract}
${ }^{1}$ School of Geosciences, University of Edinburgh, Edinburgh, UK; ${ }^{2}$ School of Biosciences, Geography and Physics, Swansea University, Swansea, UK; ${ }^{3}$ School of Geography, Planning, and Spatial Sciences, University of Tasmania, Hobart, Australia; ${ }^{4}$ Météo-France - CNRS, CNRM UMR3589, Centre d'Études de la Neige (CEN), Saint Martin d'Hères 38400, France and ${ }^{5}$ School of Engineering, Institute for Materials and Processes, University of Edinburgh, Edinburgh, UK
\end{abstract}

\begin{abstract}
To understand snow structure and snowmelt timing, information about flows of liquid water within the snowpack is essential. Models can make predictions using explicit representations of physical processes, or through parameterization, but it is difficult to verify simulations. In situ observations generally measure bulk quantities. Where internal snowpack measurements are made, they tend to be destructive and unsuitable for continuous monitoring. Here, we present a novel method for in situ monitoring of water flow in seasonal snow using the electrical selfpotential (SP) geophysical method. A prototype geophysical array was installed at Col de Porte (France) in October 2018. Snow hydrological and meteorological observations were also collected. Results for two periods of hydrological interest during winter 2018-19 (a marked period of diurnal melting and refreezing, and a rain-on-snow event) show that the electrical SP method is sensitive to internal water flow. Water flow was detected by SP signals before it was measured in conventional snowmelt lysimeters at the base of the snowpack. This initial feasibility study shows the utility of the SP method as a non-destructive snow sensor. Future development should include combining SP measurements with a high-resolution snow physics model to improve prediction of melt timing.
\end{abstract}

\section{Introduction}

Snow is an important component of the cryosphere. More than one sixth of the world's population rely on water from snowmelt for drinking water, irrigation and hydroelectricity (Barnett and others, 2005). Flooding caused by rapid snowmelt is a contributor to overall flood risk. Snow cover can also reduce flood risk because precipitation which falls as snow can be retained in the snowpack to be released to rivers slowly as snowmelts. Snow can also be a major hazard. It causes delays to ground and air transport, increases the number of injuries in accidents and can damage crops and livestock. Avalanches in mountain areas are a significant risk to property, infrastructure and life (Mitterer and others, 2011).

To predict risks and manage resources, models are used widely to forecast snow accumulation and melting. Models used operationally across the globe vary from simple accumulation and melt models based on air temperature and precipitation, to complex multilayer physically based models, such as those described in Lehning (2009); Magnusson and others (2015) and Dong (2018). Snow hydrological observations are required to drive and verify model simulations, but limitations on geographical extent, resolution and the invasive nature of some observations introduce uncertainties into model predictions (Wever and others, 2014; Largeron and others, 2020). These uncertainties are compounded by the complex behaviour of snow hydrology systems (Essery and Etchevers, 2004; Essery and others, 2013; Magnusson and others, 2015). Satellite data are used widely to assimilate into global land surface models, but despite recent advances it is not possible to measure internal water fluxes and assimilate into and verify high-resolution multilayer models (Tsai and others, 2019; Largeron and others, 2020). Manual monitoring of snow variables such as using snow pits provides high-resolution data at discrete locations (Kinar and Pomeroy, 2015), but data coverage is sparse, especially in high altitude and polar regions. Automatic monitoring of snow provides greater geographical coverage in remote locations. Liquid water in snow is an important control on many of the risks noted above, especially snowmelt runoff and avalanche risk. Measuring liquid water content using current methods has significant limitations.

Volumetric water content $\left(\theta_{\mathrm{w}}\right)$ can be measured using calorimetric methods. These measure how much heat is required to melt a known volume and mass of snow, and calculate $\theta_{\mathrm{w}}$ from this. This method is not suited to automatic operation and, due to its destructive nature, is not suitable for in situ monitoring (Kinar and Pomeroy, 2015). Electrical methods, which exploit differences in the dielectric permittivity between liquid water, air and ice, offer more promise for automatic sampling and in situ monitoring. Examples of these include the Denoth Meter, Finnish Snow Fork and Snowpack Analyzer which work using similar 
principles (Tiuri and others, 1984; Denoth, 1994), and capacitance methods (Avanzi and others, 2016). Time-domain reflectometers also make use of these principles (Stein, 1997; Pérez Díaz and others, 2017). A pulse of electrical energy with a certain waveform is sent along the probe. The time which the pulse takes to be reflected from the end of the probe, and the shape of the reflected waveform, are related to the density and water content of the snow. The Finnish Snow Fork and Denoth Meter require manual operation, and the Snowpack Analyzer is designed to make automatic in situ measurements. The Snowpack Analyzer uses a ribbon as a wave guide to make dielectric measurements, but the system is prone to wind affecting the ribbon resulting in poor contact with the snow when not fully buried (Kinar and Pomeroy, 2015). All of these dielectric methods can suffer from poor measurement accuracy due to air pockets developing around the sensors, which is particularly problematic when attempting longer-term monitoring, as found by Avanzi and others (2016).

Upward-looking Ground Penetrating Radar (upGPR) has been used to investigate snow and firn properties. For example, Sundström and others (2012) were able to reduce errors in estimates of snow water equivalent in wet snow using upGPR measurements, and Mitterer and others (2011) and Heilig and others $(2015,2018)$ carried out experiments over several seasons monitoring snowpack stratigraphy and meltwater percolation. Schmid and others (2014) used upGPR to estimate volumetric water content of snow, snow water equivalent and other snow properties. upGPR clearly has many advantages as a snow sensor, but it has high power requirements in comparison with self-potential (SP) measurements, and is of higher cost.

Global positioning system satellite receivers have been used to monitor bulk snow properties (Koch and others, 2014, 2019). By mounting one sensor above the snow, and one beneath the snow on the ground, snow water equivalent, liquid water content and snow depth can be measured using the attenuation of the GPS signal between the two sensors. These measurements were non-destructive and provided continuous records of snow properties for several seasons, but were only able to give bulk quantities, so were unable to provide information about internal water dynamics.

Liquid water behaviour in snow is complex, and is influenced by the properties of the snowpack, and by the meteorological conditions throughout the snow season. The heterogeneous structure of typical snowpacks can include strong contrasts in density and permeability, which can form at any point during the snow season and be buried under subsequent snowfalls. Snow undergoes metamorphism due to gradients of temperature, pressure and liquid water within the snowpack. Meltwater percolation in snow is affected by all these variations in snow structure, and as such is a complex mix of matrix and preferential flow; a combination of the effects of capillary forces, melting and re-freezingand hydraulic processes acting on an extremely spatially and temporally variable medium (Colbeck, 1975; Marsh, 1985; Wever and others, 2014).

Measuring snowmelt runoff at the base of the snowpack is relatively straightforward using a lysimeter (Kinar and Pomeroy, 2015). A lysimeter consists of a collecting surface typically flush with the ground level, and a method of measuring water which flows through the collecting surface, such as a tipping bucket rain gauge. Kattelmann (2000) describes how lysimeters can be used to verify snow hydrology models.

Water fluxes within the snowpack are much more difficult to measure. Dye tracing experiments can be used to study meltwater routes within the snow (e.g. Schneebeli, 1995; Campbell and others, 2006; Peitzsch and others, 2008; Williams and others, 2010), and profiles of relative saturation can be measured with dielectric techniques mentioned above. Dye-tracing experiments are time consuming, destructive and not suited to automatic monitoring.
Temperature measurements can be used to infer the water content of firn or snow such as in studies by Pfeffer and Humphrey (1996); Humphrey and others (2012) and Marchenko and others (2021). These methods are able to detect when water starts moving through the snow, but are unable to monitor how much water is moving once the snowpack reaches $0^{\circ} \mathrm{C}$.

As far as the authors are aware, direct measurements of internal water flows in the snowpack have not been published for periods covering more than a few days. Thus, there is currently a gap in our observing capability for measuring snow meltwater flows within the snowpack in an in situ automatic framework over seasonal timescales.

This paper presents the process and first results from a project to develop an electrical SP geophysical array for monitoring seasonal snow. Firstly, the SP method will be discussed, including applications to other cryosphere research and long-term monitoring studies. Then, the development and installation of the SP array at an Alpine site will be described. Then some SP data from a field season will be presented, showing the effect of meteorological and hydrological conditions on the SP signals measured. Finally, the future prospects of the SP method as a snow hydrology sensor will be discussed. Possible improvements and further research with the system described will be addressed, along with future applications to coupled electrical-hydrological modelling using multi-layer snow models.

\section{The electrical SP method}

Electrical SP measurement is a well-established technique in environmental and earth sciences. It is a passive electrical method, which measures the electrical potentials generated through several mechanisms in the medium of interest. SP measurements are useful in the respect that they measure a signal caused by dynamic processes within the material of interest, rather than structural contrasts like many active geophysical techniques such as seismic refraction and electrical resistivity tomography. SP methods are unique in their ability to measure and map subsurface water flow non-destructively over large areas. This is inherently difficult to measure, even with borehole sensors in subsurface aquifers for example, and as such, the SP method can be particularly useful in this respect.

SP measurements have been used to answer a wide variety of research questions, including locating backfilled mineshafts (Wilkinson and others, 2005), locating sinkholes in karst landscapes (Jardani and others, 2006), characterising water flow in dams (Moore and others, 2011) and monitoring volcanoes (Di Maio and others, 1997; Friedel and others, 2004). In longerterm monitoring studies, SP has been used to study subsurface hydrology (Hu and others, 2020), landslides (Colangelo and others, 2006) and water flow around trees (Gibert and others, 2006; Voytek and others, 2019). In the cryospheric sciences, SP has been used to investigate subglacial drainage (Kulessa, 2003), glacial moraine dam drainage (Thompson and others, 2012) and permafrost (Weigand and others, 2020).

Study by Kulessa and others (2012) developed a framework for modelling SP signals in laboratory snow experiments. A model relating snow properties, meltwater fluxes and the SP signals was developed and tested by melting snow under controlled conditions, and measuring the resulting SP signals. This approach was then extended to field experiments on glacial snow cover by Thompson and others (2016), who were able to map meltwater flux and liquid water content in melting supraglacial snowpacks in Switzerland. Clayton (2021) presented snowmelt flux data calculated from SP signals in snow over a few days, albeit with large errors when compared with surface energy-balance model results. 
Here, we extend this study further by adapting the manual techniques used previously into an in situ automatic SP monitoring framework for seasonal alpine snow. These are (as far as the authors are aware) the first reported results of a longer-term SP-monitoring experiment in snow; previous research has focused on shorter experiments over a few days with sensors manually positioned in the snowpack.

Snow typifies a porous medium in which there are ions freely diffusing along with bulk meltwater flow in the pore space, and ions contained within an electrical double layer at the interface between the pore space and the solid matrix composed of ice grains (Kallay and others, 2003; Kulessa and others, 2012). The inner layer contains ions that are electrochemically bound to the solid surface, creating a surface charge fixed onto the ice grains. The outer layer contains ions attracted electrostatically to these surface charges but which, due to electromagnetic interactions, can be dragged along with bulk meltwater flow to create a streaming current. The divergence of this current generates a quasistatic electric field known as the streaming potential (Sill, 1983; Kulessa, 2003; Revil and others, 2003, 2017) that can be measured with an electrode array such as described here.

Other sources of potentials can be identified: electrochemical, thermoelectric and telluric. Electrochemical potentials are caused by electrical charge separation in chemical concentration gradients (Kulessa, 2003; Doherty and others, 2010; Revil and others, 2010). Thermoelectric potentials are caused by temperature gradients leading to differing ion mobilities through the pore fluid, effectively creating chemical potentials. Telluric potentials are caused by large-scale magneto-telluric currents in the Earth's upper atmosphere, which induce currents in the subsurface (Egbert and Booker, 1992; Chave and others, 2012; MacAllister and others, 2016).

The magnitude of the SP signal is related to several properties of the snow itself, and of the meltwater percolating through it. This is described in detail in Kulessa and others (2012) and Thompson and others (2016). The flux of meltwater is the most intuitive influence on the SP, but the snow grain size, meltwater chemistry, liquid water content and snow density all have an effect on the size of signal to be measured. In this case, since we do not have detailed information about snow properties over the periods of interest, we have concentrated on using the SP signal to mark the timings of internal water flows in the snowpack, and have not attempted to calculate snow properties using the models described in Kulessa and others (2012).

In this snow case, thermal contrasts will be small, because if the snowpack is able to support the movement of liquid water, it must be isothermal at $0^{\circ} \mathrm{C}$. Similarly, we expect chemical differences to be relatively small due to the snowpack being mature with preferential elution of ions having already taken place. This means that changes in the conductivity and $\mathrm{pH}$ of the snowpack will have already occurred, and these properties can be assumed to be approximately constant over the time covered by the experiments. Therefore, we expect the dominant source of potentials measured will be streaming potentials caused by the movement of meltwater through the snow. These potentials were expected to be of the order of $10-100 \mathrm{~s}$ of millivolts, as reported in Thompson and others (2016) and Clayton (2021).

\section{Scientific aims and system requirements}

The aim of this study was to create a measurement array capable of continuously monitoring the SPs generated by streaming currents caused by meltwater flow in a seasonal snowpack. Electrical potentials are measured with respect to a reference potential, and provide a voltage between pairs of electrodes. These potentials are caused by water movements in the snowpack which are difficult to measure non-destructively. These measurements should therefore allow greater understanding of the processes governing meltwater percolation in snow. This will in turn help improve modelling these processes. Better modelling of liquid water in snow should then deliver improvements to avalanche and flood risk forecasting.

In order to understand the processes affecting the SP signals, the array needed to be accompanied by a full range of meteorological and hydrological observations. The system needed to be able to make measurements in a non-invasive fashion in order to preserve the snow in as close to its 'natural' state as possible. It also needed to be durable and rugged enough to withstand a whole winter of subzero temperatures, along with the demands of wind and snow loading. Because of the remote nature of snow research sites, remote control of the data logging systems and the ability to download data over the internet was crucial to avoid multiple expensive site visits.

\section{SP array development and installation}

\section{Field site and companion meteorological and hydrological data}

The experiment was carried out over a winter season at the snow research station at Col de Porte, in the Chartreuse Alps in southeastern France. The site is a mid-elevation meadow site located at $\sim 1325 \mathrm{~m}$ altitude, and is surrounded by mixed forest. A detailed description of the Col de Porte site, datasets and associated quality control processes is provided in Lejeune and others (2019).

Snow cover is typically observed from early December until mid-April. Snow depths typically reach a maximum of between 0.75 and $1.50 \mathrm{~m}$, but due to the relatively low elevation, positive temperatures and even rainfall are possible throughout the winter. This makes the site ideal for the study of liquid water processes in snow, with the possibility of several melt cycles and rain-on-snow events each winter. Table 1 shows meteorological data available at Col de Porte relevant for this study.

The site slopes gently to the northeast, and the conditions for lateral flow through or beneath the snowpack as described in Eiriksson and others (2013) will be met. The lysimeters measuring basal runoff are located a few metres upslope of the geophysical array.

In addition to the automatic data in Table 1, manual snow pit measurements are made approximately weekly through the snow season following standard snow hydrology protocols (Fierz and others, 2009) which provide snow density, grain size, hardness and temperature profiles. In addition to the routine measurements made by Meteo France staff, daily manual snow pit measurements were made for 1 week in March 2019, and dye tracing experiments were carried out to qualitatively assess meltwater percolation (Campbell and others, 2006; Kinar and Pomeroy, 2015). Rhodamine B dye in powder form was mixed with water, then poured evenly onto a marked $1 \mathrm{~m}$ square using a gardening watering can with a sprinkler attachment. The snowpack within this area was then excavated to the ground after $3 \mathrm{~h}$ allowing the dye percolation to be observed in the snow pit wall. Daily webcam images provided by Meteo France were available to help monitor the system state and snow cover.

An energy-balance snow hydrology model was run with the in situ data from Col de Porte to simulate the melting generated at the snow surface. The model used was Factorial Snow Model (Essery, 2015) which gave hourly output.

\section{Array design and installation}

With the criteria set out above in mind, the geophysical array was designed to be an 'inverse borehole' with electrodes arranged on 
Table 1. Hourly meteorological and hydrological data available at Col de Porte

\begin{tabular}{ll}
\hline Variable & Units \\
\hline Snowfall rate & $\mathrm{kg} \mathrm{m}^{-2} \mathrm{~s}^{-1}$ \\
Rainfall rate & $\mathrm{kg} \mathrm{m}^{-2} \mathrm{~s}^{-1}$ \\
Air temperature $(1.5 \mathrm{~m}$ above snow surface) & $\mathrm{K}$ \\
Relative humidity $(1.5 \mathrm{~m}$ above snow surface) & $\%$ \\
Wind speed $(10 \mathrm{~m})$ & $\mathrm{m} \mathrm{s}^{-1}$ \\
Snowmelt runoff & $\mathrm{kg} \mathrm{m}^{-2} \mathrm{~s}^{-1}$ \\
Snow depth & $\mathrm{cm}$ \\
Snow surface temperature & $\mathrm{K}$ \\
Downwelling long wave radiation & $\mathrm{W} \mathrm{m}{ }^{-2}$ \\
Downwelling short wave radiation & $\mathrm{W} \mathrm{m}{ }^{-2}$ \\
\hline
\end{tabular}

poles that would be gradually buried by the snow through the winter. The array was composed of four poles, each with ten electrodes equally spaced up each pole, making 40 electrodes in total. The poles were constructed from $2 \mathrm{~m}$ long $32 \mathrm{~mm}$ diameter hollow poles made from white polyvinylidene fluoride plastic. The poles were arranged in a square with spacing of $75 \mathrm{~cm}$ (see Fig. 1). The spacing and size of the array was partly constrained by the size of the area available for installation, and partly due to the poles also having electrical resistivity electrodes attached to them (data not reported here).

The array was designed to replicate the potential amplitude manual survey method set out by Corry and others (1983) and adapted to glacial snowpacks (Thompson and others, 2016). This method employs a fixed reference electrode buried near to, but outside of, the main survey area, and then a roving electrode which is used to measure the SP over a regular grid. Since ours was a monitoring study, instead of having a roving electrode, multiplexer chips were used to switch measurements between a regular array of electrodes.

By having electrodes spread on four poles in a square it was hoped that differences in readings between poles could be related to lateral differences in meltwater percolation in the snowpack. Similarly, the differences between readings from electrodes at different heights were intended to be related to the motion of meltwater on its journey from surface melt or rainwater input to basal runoff.

It is recognised that point measurements such as the SP measurements and the meteorological and hydrological data they were compared to are likely to exhibit differences due to heterogeneities across the site. By siting the array in an open and level part of the site, the data will be representative of the wider site.

\section{Reference electrodes}

The reference electrodes were non-polarising lead/lead-chloride SP electrodes of the Petiau type (Petiau, 2000) buried next to the main array $\sim 10 \mathrm{~cm}$ deep in the soil, which was considered to be sufficiently deep, as thermal effects from diurnal heating were not a concern when the ground was covered in snow. Petiau electrodes were used for the reference electrodes because they produce stable readings over longer periods. They have a porous end which needs to remain damp to maintain good electrical contact, and because they were buried in the soil this condition was met over the winter period.

\section{Pole electrodes}

Petiau-type electrodes are too big to mount on poles. Manufacturing smaller bespoke Petiau-style electrodes was considered (as in Kulessa and others, 2012), but they also need to be kept damp to maintain electrical contact. This would not be possible for extended periods of time above the snow as the snowpack builds up before burial. Therefore, the electrodes for the poles were manufactured from lead sheeting and mounted on the poles. Kulessa (2003) used solid lead electrodes for monitoring experiments over a whole year. This corroborated their water bath testing and general expectations that lead is inert and nonpolarisable. The lead strip electrodes employed here gave stable SP readings in water baths for several days. A lead electrode is shown in Figure 1c. They were constructed as strips of lead wrapped around the pole to provide a large surface area for contact with the snow, while remaining flush with the pole to reduce the possibility of snow compaction ripping them off.

\section{Wiring arrangement}

The electrodes were wired up to form 43 pairs of electrodes between which differential voltage measurements were made. These consisted of three reference pairs between the six reference electrodes, and then 40 dipoles between a reference electrode and a pole electrode. Three pairs of reference electrodes were required because three multiplexer chips were used. The measurements were made using a Campbell Scientific CR1000 datalogger, with multiplexer chips used to switch between the pole electrodes.

\section{Temperature measurements}

In addition to the SP measurements, two PT100 thermistors were mounted on one of the poles, one at $\sim 30 \mathrm{~cm}$ height and one at 60 $\mathrm{cm}$ height. The PT100 thermistors were found to be useful to help verify whether the lower electrodes were buried or not. This was not possible by viewing the webcam images alone.

\section{Data collection and processing}

SP voltages were measured every $5 \mathrm{~s}$ between all 43 pairs of electrodes. The PT100 temperatures were measured once per minute. $\mathrm{SP}$ was measured at each electrode giving $40 \mathrm{SP}$ values. Data measured at $5 \mathrm{~s}$ intervals showed diurnal and shorter-term variability overprinted on longer-term SP changes. To remove this shorterterm high-frequency variability and longer-term changes, the data were detrended, and then averaged at a $30 \mathrm{~min}$ interval. This preserved the diurnal fluctuations in the signal that we could relate to meteorological and hydrological data available to us.

\section{Results from winter $2018-19$}

The system was installed at the end of October 2018. There were some short-lived shallow snowfalls in October and November, then lasting snow fell in December. It was not of sufficient depth to cover the array until further snowfall during January and early February. Snow depth reached a maximum of $\sim 165$ $\mathrm{cm}$ during early February, which completely buried the poles. It then compacted and thawed through the rest of February with the exception of two small snowfalls. Some snowfall in the first half of March was followed by a prolonged period of melt. There was another snowfall in early April of $\sim 40 \mathrm{~cm}$ which reburied the lower electrodes meaning SP measurements were possible for a longer proportion of the melt season (see Fig. 2). Here, we introduce results from two periods of particularly insightful snowpack conditions and compares the SP measurements to the concurrent hydrological and meteorological conditions.

\section{Uncertainty and error quantification}

Reference measurements, dry snow and free air measurements The reference measurements were generally stable, although some high frequency variations were present in the raw data. The reference readings had no notable diurnal (or other period) cycles apparently. Table 2 shows the mean and std dev. of the reference electrode measurements. Reference 1 showed more variation than 


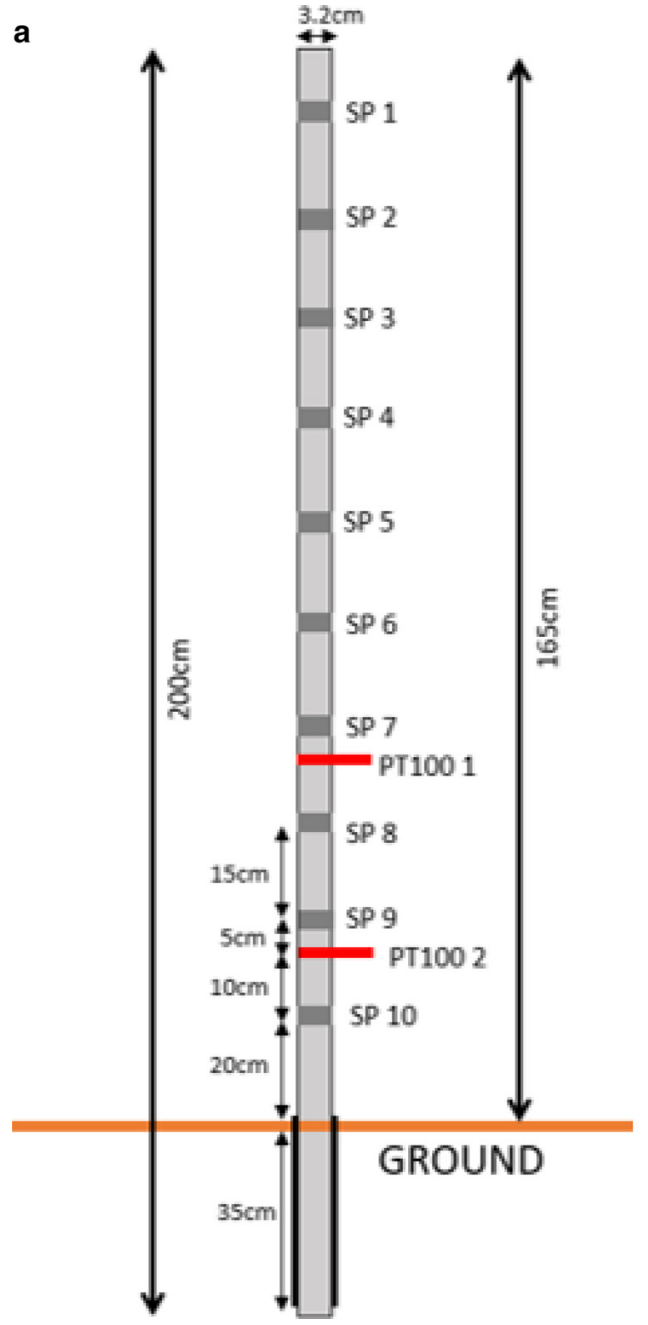

b

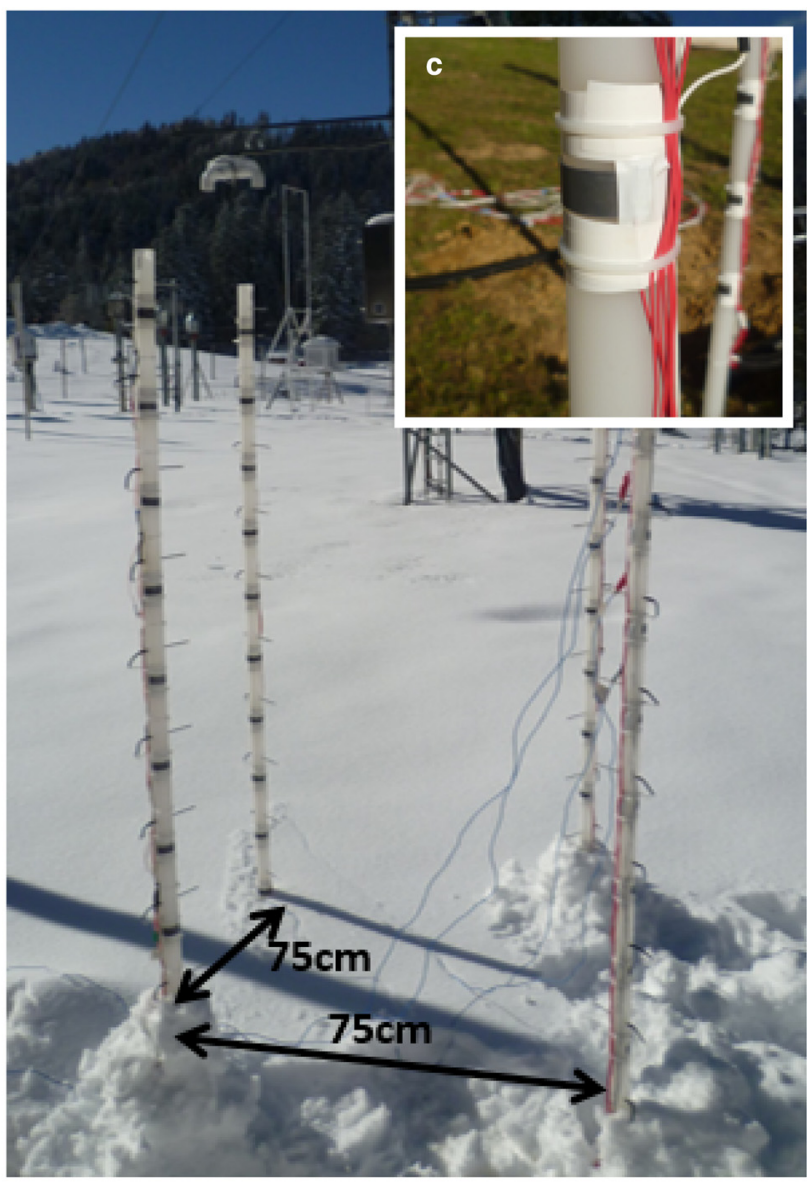

Fig. 1. (a) Schematic of a pole showing SP electrode spacing and location of PT100 thermistors (only mounted on one pole). (b) Photograph of poles during installation in October 2018, with an early snowfall. Pole spacing is marked. Snow around the poles was disturbed during installation but was expected to thaw before lasting snow fell later in the autumn. Electrical resistivity electrodes are also visible. These data are not reported here. (c) Close up view of lead strip SP electrode.

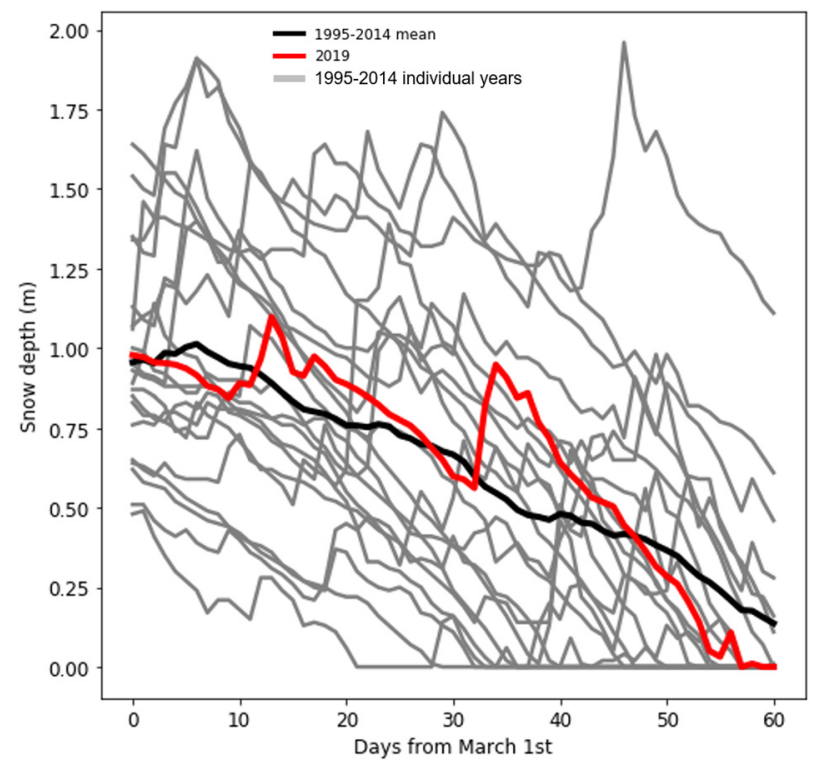

Fig. 2. March and April 2019 snow depth at Col de Porte plotted alongside 1995-2014 and long-term mean.

2 and 3 with a std dev. of $29.9 \mathrm{mV}$ versus $10.8 \mathrm{mV}$ and $4.8 \mathrm{mV}$ respectively. Once the reference readings had been smoothed in the same way as the pole readings, the variation was negligible
Table 2. Mean reference voltage and std dev. for 21 March-14 April 2019

\begin{tabular}{lcc}
\hline Electrode pair & Mean differential voltage $(\mathrm{mV})$ & Std dev. $(\mathrm{mV})$ \\
\hline Reference 1 & -4.8 & 29.7 \\
Reference 2 & 10.8 & 10.8 \\
Reference 3 & 0.4 & 4.8 \\
\hline
\end{tabular}

compared to the magnitude of the signals associated with meteorological and hydrological factors seen in the pole readings. Figure 8 shows the SP signals associated with electrodes melting out and being exposed above the snow surface. Once the electrodes are exposed a diurnal cycle is not visible.

Figure 3 shows the difference between SP signals measured within the snowpack and above the snow exposed in air. It is clear that the measurements in air are noisier, and they do not exhibit cycles such as the clear diurnal cycle visible in the buried SP measurements. The standard error of the mean of the measurements in the snow is smaller than the measurements in the air.

Figure 4 shows measurements from electrodes buried in cold dry snow. There is still an SP signal being generated, but it does not exhibit a diurnal cycle as the snowpack was not experiencing any melting. The magnitude of the SP signal is $\sim 30-50 \mathrm{mV}$ which is lower than the magnitudes of variations observed when a clear meltwater signal was present in late March and mid-April. 


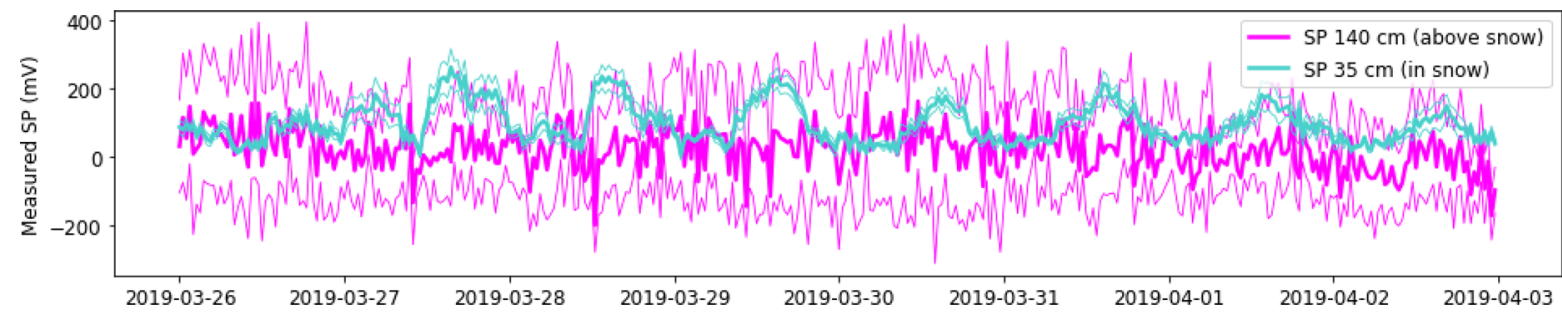

Fig. 3. Example period from late March to early April 2019 showing difference between SP measurements in the snowpack and exposed in air above the snow. Standard error of the mean plotted in thin line style. Note the difference in error magnitude for electrodes buried versus electrodes above the snow. Above snow mean error for this period is $146.2 \mathrm{mV}$ compared with $20.6 \mathrm{mV}$ when buried in snow.

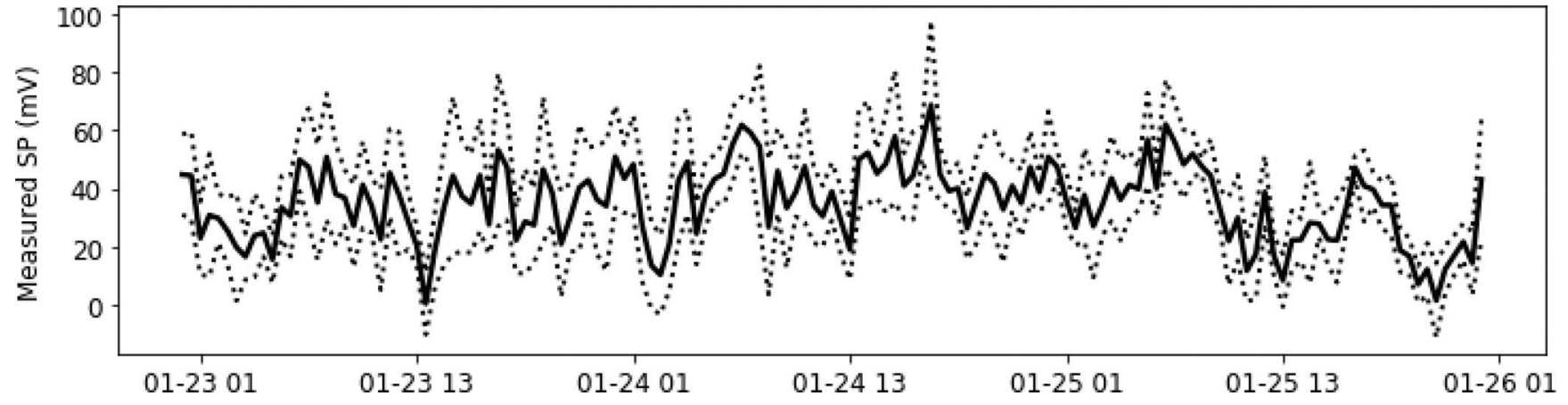

Fig. 4. Example period from late January 2019 showing the signal from electrodes buried in dry cold snow, with standard error of the mean plotted with dotted line. Mean error over this period in dry snow was $13.2 \mathrm{mV}$.

\section{Lateral and vertical variation in readings}

As described above, it was hoped that lateral and vertical differences would be discernible in the measurements. Unfortunately, it was impossible to discern any coherent lateral differences between the four poles. Similarly, coherent vertical differences in timing were not visible in the data from electrodes at different heights within the snow, although it was possible to differentiate between those electrodes that were buried and those that were not (Fig. 3). Because of this, the analysis that follows concentrates on mean measurements from the four electrodes at each height, and does not consider vertical or lateral changes in the signal.

\section{SP signals during diurnal melting in spring}

\section{Meteorological and snow cover conditions in March 2019}

March 2019 gave mixed conditions with some periods of snowfall, some rainfall, but temperatures often above freezing (see Fig. 5). Snow depth was around average for the time of year compared to previous years (Morin and others, 2012; Lejeune and others, 2019) (see Fig. 2). During late March, there was a prolonged period of snowmelt following a clear diurnal cycle. This was caused by a period of anticyclonic atmospheric conditions giving warm sunny days with ablation driven by solar radiation, and cool or cold nights with conditions ideal for radiative cooling and overnight refreezing. Air temperatures in the middle of the day reached as high as $15^{\circ} \mathrm{C}$, but snow-surface temperatures overnight fell to below minus $10^{\circ} \mathrm{C}$ on several nights (see Fig. 6b). This period of marked diurnal melt/freeze cycling persisted into early April. During this period, snow depth was initially $\sim 90 \mathrm{~cm}$, falling to $\sim 60 \mathrm{~cm}$ by the end of March. In Figure 5, this period of snowmelt is clearly seen from around 21st March in the observed snow depth, accompanied by predominately positive air temperatures. Thawing takes place every day from this date onwards. Figure $6 \mathrm{~b}$ shows the snow-surface temperature reaching $0^{\circ} \mathrm{C}$ each day, indicating thawing is taking place. Within the snowpack, the temperature remained close to $0^{\circ} \mathrm{C}$, which supports the assumption made earlier that thermoelectric potentials will be negligible within the snowpack. As the snow depth reduced, the PT100 sensor mounted $60 \mathrm{~cm}$ above the ground became exposed and recorded positive temperatures in the daytime when exposed to solar radiation. Although thawing is occurring at the snow surface every day during this period, there is a slight lag before runoff starts being recorded in the lysimeters (Fig. 6d). From around the 24th March onwards, a daily peak of runoff is observed, increasing to a peak flow of $\sim 2 \mathrm{~kg} \mathrm{~m}^{-2} \mathrm{~h}^{-1}$ by the end of March. This shows that the snowpack is able to support liquid water flow through its full depth from around 24th March onwards.

Dye-tracing experiments carried out on the 19th and 20th March (Fig. 7) show that most of the snowpack was able to support meltwater flow. In these qualitative experiments to investigate the meltwater percolation, several layers were visible, and vertical and horizontal flow and preferential flow fingers were observed. It was found that dye reached the lowest layers of the snowpack in $2-3 \mathrm{~h}$, but instead of continuing to percolate to the base of the snowpack, it then flowed horizontally down a slight gradient along a layer interface, marked in Figure 7. This layer interface was at $\sim 15 \mathrm{~cm}$ above the ground so was below the lowest SP electrode on the pole but above the reference electrodes. Snow pit observations established that there were no ice layers or lenses at this depth in the snowpack, and that the interface that the dye flowed along marked a relatively small change in density, but with similar size snow grains. The stratigraphic contrast was also observed in snow pit observations on 28th March, albeit with a smaller density contrast. This was $\sim 5 \mathrm{~d}$ after the lysimeters started to record runoff, showing that despite the layer interface persisting, the snowpack could support water flow right to the base.

Measured SP signals during late March 2019

As discussed above, the snowpack was able to support liquid water flow during late March. Therefore, we expected to be able to measure SP signals generated by this fluid flow in the snowpack. Preferential melting had occurred around the poles so the snow depth covering the pole was lower than the measured snow 


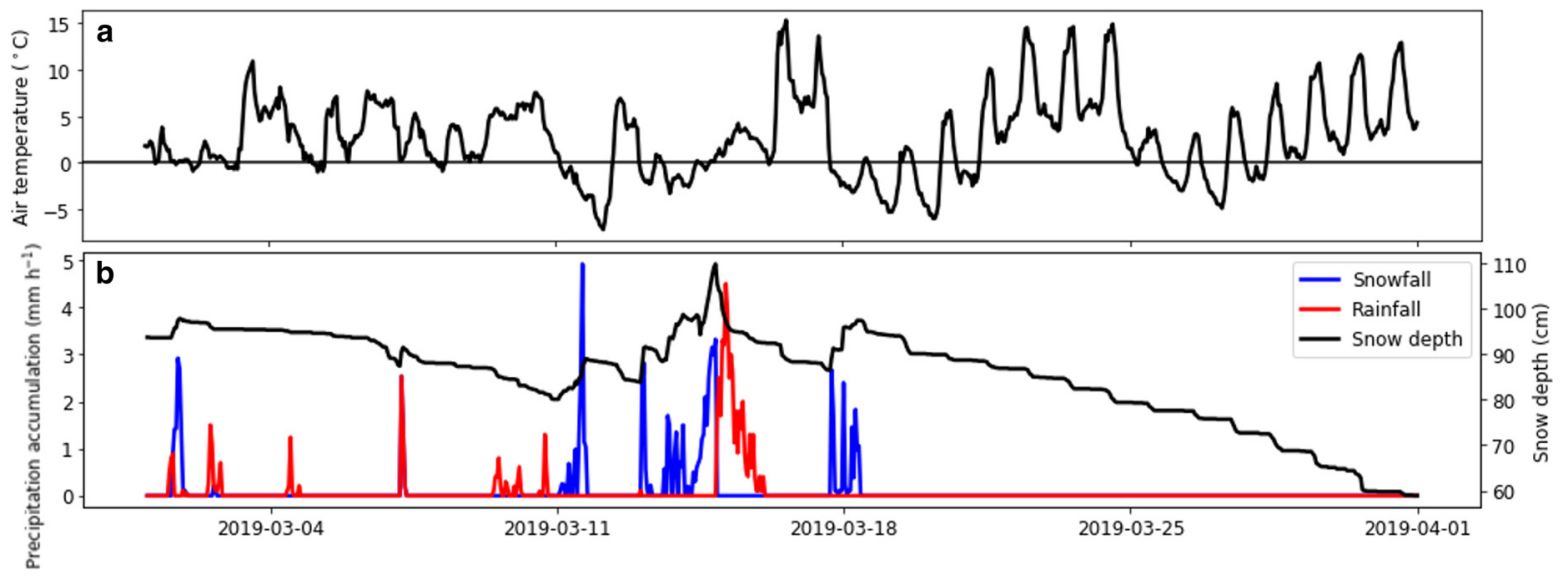

Fig. 5. (a) Observed air temperature at Col de Porte for March 2019. (b) Observed precipitation and snow depth at Col de Porte.
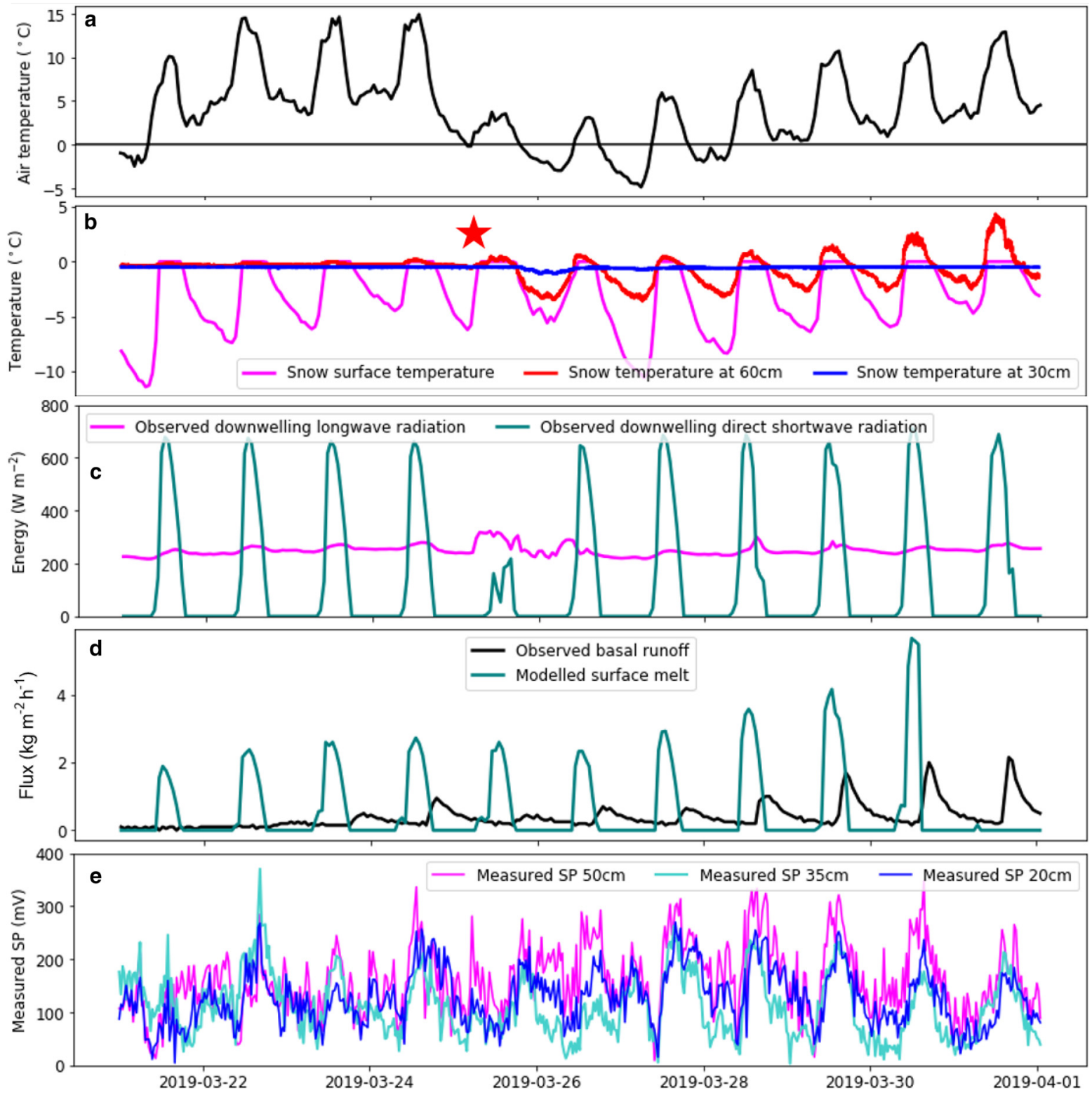

Fig. 6. Meteorological, hydrological and SP measurements for late March 2019. (a) Observed air temperature. (b) Observed snow surface temperature, and temperatures measured using PT100 thermistors at 30 and $60 \mathrm{~cm}$ above ground level for late March 2019. The red star indicates the approximate time from which the $60 \mathrm{~cm}$ thermistor was exposed (see cavities in Fig. 9). (c) Observed downward longwave and shortwave radiation. (d) Observed basal runoff from Meteo France lysimeter, and modelled FSM surface melt. (e) Mean SP from the four electrodes at each height buried in the snow. The mean standard error of the mean over this period was $39.9 \mathrm{mV}$ at $50 \mathrm{~cm}, 21.4 \mathrm{mV}$ at $35 \mathrm{~cm}$ and $23.5 \mathrm{mV}$ at $20 \mathrm{~cm}$. 


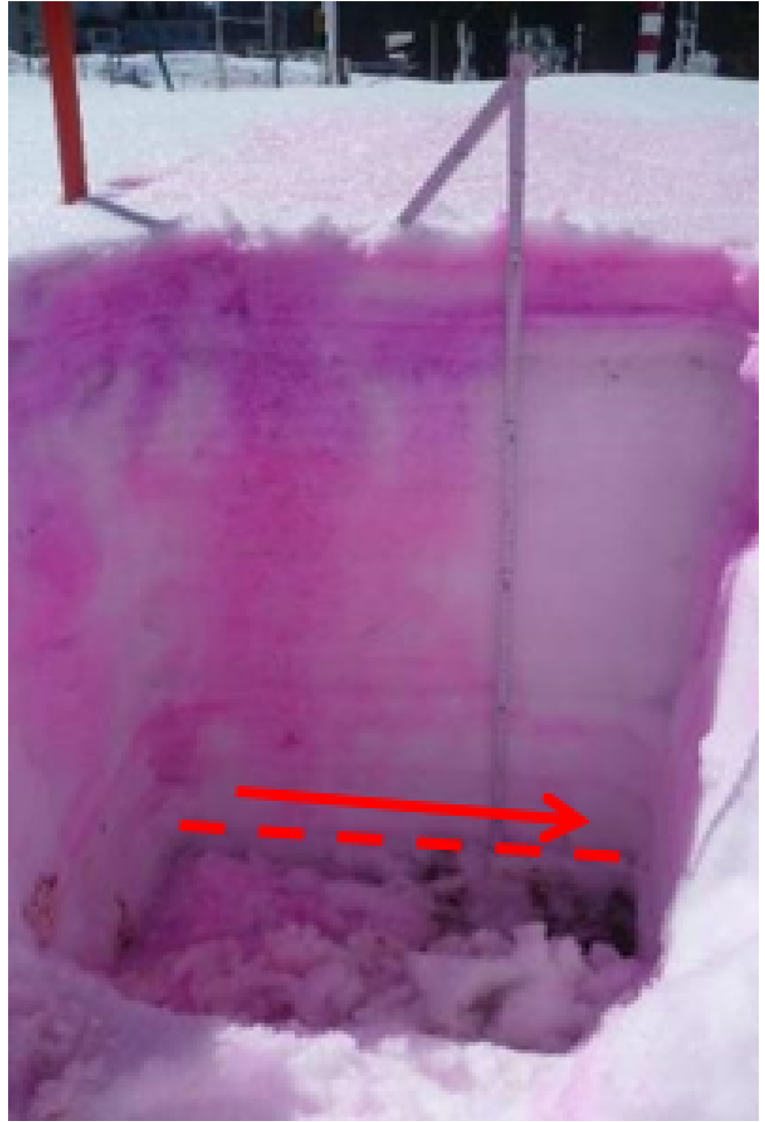

Fig. 7. Dye-tracing experiment carried out on 20th March 2019. The density contrast, along which horizontal flow occurred, is marked.

depth elsewhere. With a snow depth of $\sim 90 \mathrm{~cm}$ at the beginning of the period, the top five SP electrodes on each pole were exposed, and by the end of the period with a depth of $60 \mathrm{~cm}$, only the lowest three electrodes were reliably buried by the snow. Therefore, the data from the top seven electrodes on each pole were neglected. From Figure 1, it can be seen that the three lowest electrodes on each pole are at heights of 20,35 and $50 \mathrm{~cm}$ above the ground.

In Figure 6e, a diurnal pattern is visible in the signals from the buried SP electrodes at the three lowest heights on the poles. Some days exhibit multiple peaks, and especially towards the end of the period, a clear daily signal is visible. The peak of the cycles are generally during the afternoon, with the minima overnight. This supports the assumption that the SP peaks are caused by diurnal melt flow. The peaks of each diurnal cycle increase in magnitude from around 24th March, which is when the lysimeter started recording runoff. However, the fact that there is still a diurnal peak before then supports the assumption that early in the period the SP signals are being generated by internal melt flow which is not reaching the base of the snowpack.

\section{SP signals during a rain-on-snow event}

Meteorological and snow cover conditions in mid-April 2019 After the period of prolonged melt in late March, heavy snowfall occurred early in April which increased the snow depth to $\sim 110$ $\mathrm{cm}$. Further periods of thaw and some further snowfall occurred through to mid-April. Late on the 9th April, there was a small rain-on-snow event, then on the afternoon of the 10th April there was another, larger rain-on-snow event. There was no snowfall during this period. Figure $8 \mathrm{~b}$ shows the air temperature remaining above freezing during and after these rainfall events.
Snow surface temperature remained at $0^{\circ} \mathrm{C}$ until the night of the 12th April, so thawing can be assumed to have been taking place until then, with refreezing taking place that night followed by melting again the following day. Snow depth was initially $\sim 70 \mathrm{~cm}$ on the 9th, falling to $\sim 52 \mathrm{~cm}$ by the morning of the 13th. The temperature measured at $30 \mathrm{~cm}$ above ground remained $\sim 0^{\circ} \mathrm{C}$ throughout, indicating that electrodes below that height would be buried. However, the PT100 at $60 \mathrm{~cm}$ recorded positive temperatures on each day, so it is assumed that electrodes around this height were not completely buried by the snow. Figure 9 shows a snapshot from the Meteo France webcam on 12th April. Cavities around the poles are visible, which explains why the electrodes and upper PT100 were not buried despite the observed snow depth nearby being sufficient earlier in the period.

Figure $8 \mathrm{e}$ shows the observed rainfall, along with measured basal runoff and modelled surface melt. A clear peak in runoff is visible after each rainfall event. These peaks do not occur during the mid-afternoon as would be the case from diurnal melting. Before the first peak (runoff 1 ) there is a peak in modelled surface melt which will have supplied some liquid in addition to the rainfall at rain 1 . The second peak (runoff 2) follows rain peak 2 , and in this case there is no surface melt input. For runoff peaks 3 and 4, the runoff reverts to a diurnal cycle driven by solar radiation, which can be seen from the shortwave radiation and air and snow temperature peaks, although this is not reproduced by the model. Both the lower PT100 measurements and the Meteo France snow profiles carried out nearby show an isothermal snowpack at $0^{\circ} \mathrm{C}$ which could therefore support meltwater percolation to its base.

\section{Measured SP signals during mid-April 2019}

As discussed above, by mid-April the snow depth was not sufficient to cover many electrodes, with the preferential melting that occurred around the poles reducing the buried electrodes to those at 20 and $35 \mathrm{~cm}$. Unfortunately, the measurements from the lowest level (at $20 \mathrm{~cm}$ ) had shown evidence of longerterm changes in the SP signal by this stage of the season. We were unable to relate these changes to the observational data available. The electrodes at $35 \mathrm{~cm}$ appeared to give plausible readings, so the discussion of the rain-on-snow event and its SP signatures refer to measurements made at this level. The data from the electrode at $50 \mathrm{~cm}$ have been left in Figure 8 to show the response as it melts out and becomes uncovered.

In Figure 8f, a small peak (SP 1) in SP is visible on the evening of the 9th which occurred during the first period of rainfall. The associated peak in runoff (runoff 1 ) is slightly delayed from the peak in rainfall (rain 1), reflecting the time required for the water to percolate to the base of the snowpack. On the 10th, two SP peaks are visible. The first (SP 2) is smaller and occurs around noon. This is due to surface melting taking place. The air temperature was above freezing along with a peak in incoming shortwave radiation, and the snow surface was at $0^{\circ} \mathrm{C}$. The second much larger peak (SP 3) occurs at the same time as the second rainfall event (rain 2), which was heavier than the first with hourly accumulation of over $6 \mathrm{~kg} \mathrm{~m}^{-2}$ compared to $\sim 2 \mathrm{~kg} \mathrm{~m}^{-2}$ for rainfall 1 . The peak in runoff (runoff 2 ) begins to occur before the rainfall, so it was probably registering runoff from surface melt first, and then percolation of rainwater. A further small peak (SP 4) is registered in the SP signal during the evening of the 11 th, and it is not clear why this did not occur earlier when more melting will have been taking place. The runoff follows a similar pattern however, with a small peak (runoff 3 ) on the evening of the 11th too. Then, on the 12th, surface melting drives a broad peak in the SP signal (SP 5), which occurs just before a large peak (runoff 4 ) is recorded in the runoff. From the 13th 

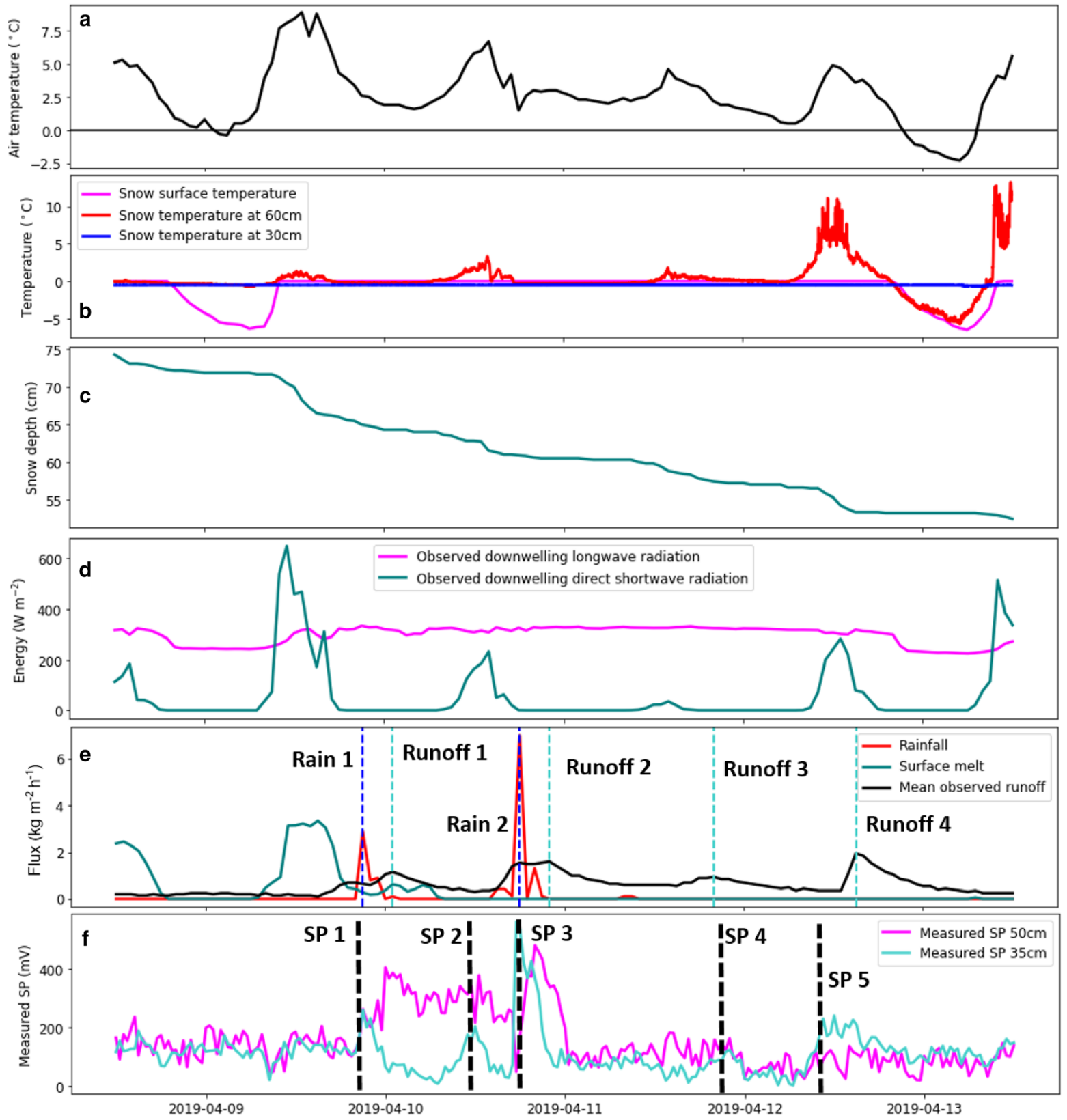

Fig. 8. Meteorological, hydrological and SP measurements for April 2019. (a) Observed air temperature. (b) Observed snow surface temperature, and PT100 temperature on poles at 30 and $60 \mathrm{~cm}$. (c) Observed snow depth. (d) Observed incoming long- and shortwave radiation. (e) Observed rainfall, modelled surface melt and observed basal runoff. (f) Mean observed SP signal from all electrodes at 35 and $50 \mathrm{~cm}$. Mean standard error of the mean for this period was $55.5 \mathrm{mV}$ at $35 \mathrm{~cm}$ and $32.6 \mathrm{mV}$ at $50 \mathrm{~cm}$.

onwards, it is not clear if the electrodes were sufficiently buried in the snow to make sensible measurements.

\section{Discussion}

In this section, the success of the SP measurement array in seasonal snow is evaluated against the scientific aims defined above. The system's utility in detecting snowmelt percolation events is discussed. Finally, an outlook is given for future research in seasonal snow building upon this feasibility study.

\section{Monitoring SP signals of melting seasonal snow}

With respect to the aims set out above, SP signals were successfully measured for a winter season at an Alpine site. Some gaps in the data were present due to power outages, and a significant amount of the data was not used because the snow cover was not deep enough to cover all the electrodes. However, for two interesting periods of snow conditions enough data were available to investigate the associated SP signals.

The system was designed to withstand the demands of an alpine winter season, and it did generally prove to be durable enough. However, by the end of the season it was clear that the poles had moved due to a combination of ground heave, and snow settling and movement. Due to the gentle slope in the topography, snowpack crept along this gradient over the course of the season. This bent the poles and moved one of them several centimetres further into the ground than when initially installed. The electrodes themselves remained well-attached to the poles and provided stable readings, although the drift noted in the lowest layer of sensors by the April rain-on-snow event was an exception. It is possible of course that many more electrodes would have recorded drift or spurious readings if they were buried in the snow for longer, but when they were in the open air the readings 


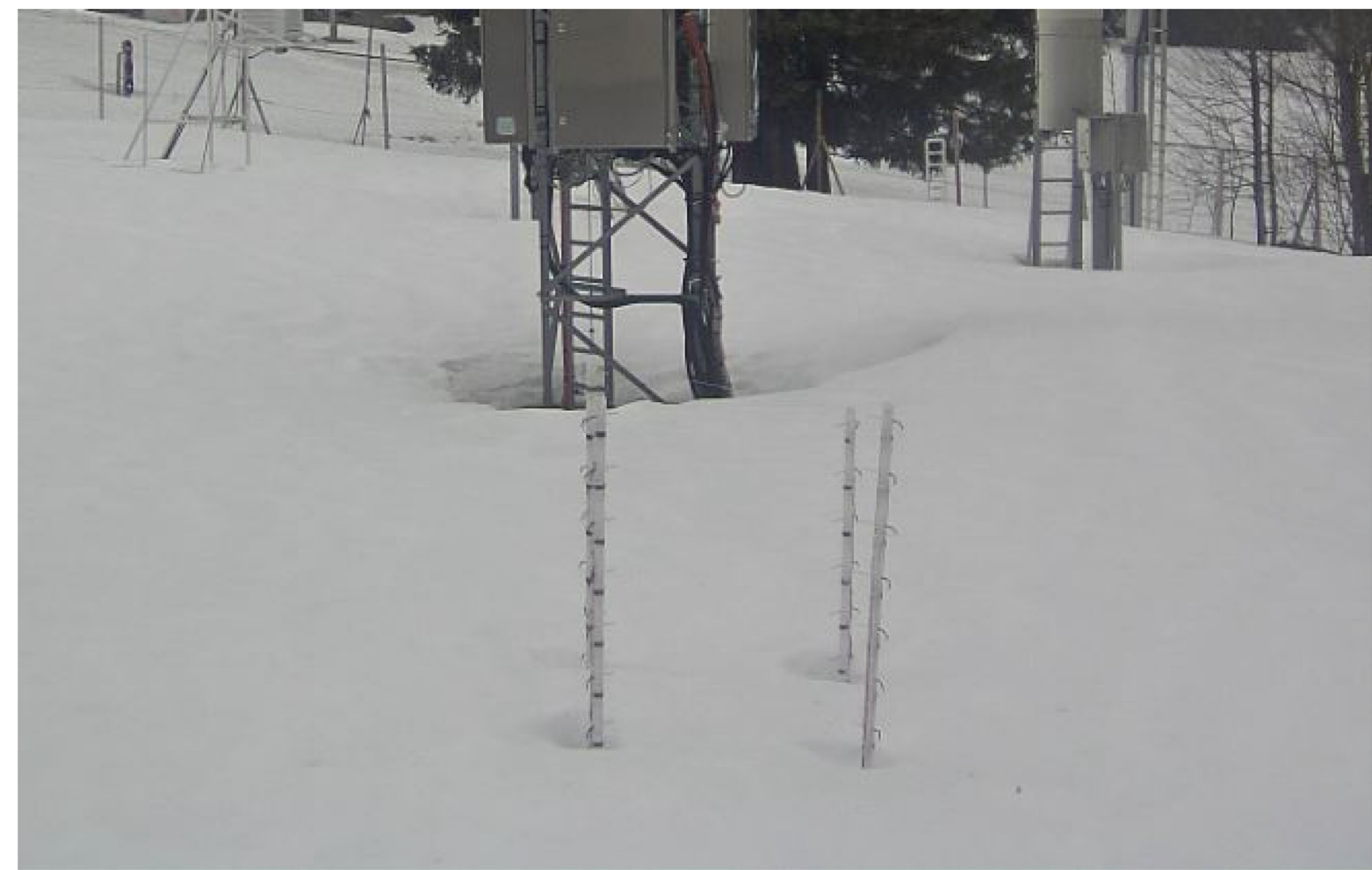

Fig. 9. Meteo France webcam image from midday on 12th April showing preferential melting has created cavities around the poles, exposing more electrodes than might be expected from the observed snow depth.

were noisy and subject to temperature fluctuations (as high as tens of degrees Celsius on sunny days followed by clear nights) so any drift was difficult to distinguish from other effects.

During the period of diurnal melting driven by solar radiation in late March, a clear diurnal cycle was visible in the SP signals, which ties in with expected generation of surface melt. SP signals were registered within the snowpack before runoff was detected in the lysimeters, showing the utility of the SP method as an internal meltwater flow sensor. The signals from the three different heights of measurement did not show any evidence of the highest sensors registering a signal first, followed by the lower ones as meltwater percolated vertically through the snow. The dye-tracing experiments showed the high speed of water percolation in this ripe snowpack which could explain the coincidence of peaks at all three levels. However, a more likely explanation is due to preferential flow along and near the poles delivering meltwater past the electrodes at roughly the same time. Additionally, the depressions that formed around the poles may have helped meltwater to preferentially flow towards and down the poles. In this context, although the method was as non-invasive and non-destructive as possible, it is likely that the measurement equipment has influenced the measurements to some degree.

In the rain-on-snow event that occurred in mid-April, clear peaks in the SP signal were attributable to both rainfall percolating through the snow, and subsequent surface melting due to positive air temperatures. However, by this stage in the season, preferential melting around the poles had exposed all but two levels of electrodes, and one of these levels had begun to give spurious readings. It was still possible to see clear peaks in the one remaining level of usable data though. The SP peaks occurred earlier than the lysimeters registered peak runoff, again showing the utility of the SP method as a sensor of internal flows. With only one level of electrode data available, it was not possible to compare peaks in SP at different levels, but it is expected that the same preferential flow will have occurred close to the poles.

\section{Key limitations and advantages of the system}

After the deployment of the system for a winter season, it is possible to assess the limitations and sources of uncertainty in the measurements made, and also to note the advantages such a system holds over traditional measurement technology.

After this preliminary experiment, it is clear that the SP system required a deep snowpack in order to bury enough electrodes to get usable readings. For a significant part of the winter season, right through to January, the snowpack was not deep enough to bury enough electrodes. Later in the season, the problem of preferential melting around the poles became more of an issue, with over $50 \mathrm{~cm}$ of observed snow not enough to bury more than the lowest electrodes. This preferential melting, causing depressions around the poles, may have contributed to preferential flow occurring along the poles. However, despite these limitations, some useful data were measured which could be related clearly to meteorological and hydrological factors.

The long-term drift in some of the readings which affected the April rain-on-snow data was investigated and there was not a clear cause. It was not related to some electrodes being connected to one multiplexer, as the four electrodes at that height were connected to three different multiplexers and three different reference electrodes and all exhibited similar drift. Poor electrical contact could have developed through air gaps melting, or it is possible that the electrodes at that level had been damaged through snow creep and compaction. This could have affected the connection to the electrodes or the cables attaching them, but it was not possible to verify this with a site visit.

The data measured on the poles showed fluctuations at high frequencies. It is difficult to attribute these fluctuations to issues with the electrodes which may have developed over the length of the winter season without having other electrodes or locations to compare to. It is worth noting that the reference dipoles composed of Petiau electrodes were very stable throughout, with little 
to no drift. It is not clear whether air gaps developed around the electrodes, and is therefore difficult to assess the quality of the electrical contact between snow and electrodes. This could have contributed to the high-frequency fluctuations which were observed. The array was sited by necessity in a location with a number of sources of electrical noise, from both buildings and equipment at the Centre d'Etude de la Neige, and the adjacent ski lift infrastructure. It is therefore likely that these highfrequency fluctuations were caused by a combination of poor electrical contact, electrical noise from the surroundings and poorly understood electrode drift effects.

Spatial variability was observed between the SP array and the Meteo France observations. This was most apparent in the snow depth, where differences between the Meteo France measured snow depth and that observed at the poles were greater than $20 \mathrm{~cm}$ by 12th April. Although clearly the internal structure of the snowpack will have varied across the site, we assumed that surface melt and precipitation inputs were constant across the site in our analysis, and this will have contributed to uncertainty.

Despite these limitations, the system showed advantages over other measurement systems. It was able to detect meltwater percolation within the snowpack before it reached the lysimeters. This is a key advantage, as timing of wetting front propagation through snow is very difficult to measure non-invasively. However, the likelihood of preferential flow along the poles precludes any significant conclusions being drawn regarding meltwater timings, along with the fact that vertical differences in readings were not coherent. However, the SP system was able to carry out bulk measurements of meltwater timings with some success, especially in the late March melting period. An advantage of this system over more complex ones is its simplicity and low cost. The electrodes, poles and cabling were easy to manufacture, and data loggers are relatively inexpensive to purchase. Due to this low cost, it would be possible to deploy SP arrays at a number of sites with relative ease.

Co-location of the SP system at the Col de Porte observatory provided high-quality meteorological and hydrological observations, which were essential to understand processes affecting the SP signals. Without these, a full suite of observational equipment would have needed to be installed in order to fully interpret the SP results.

\section{Possible future research and developments}

It is possible to note some improvements which could be made to the system to address some of the limitations outlined above. Clearly, the number of electrodes which were actually buried in the snowpack was too low, so an obvious improvement would be to position more electrodes lower on the poles, and put them closer together. For a site like Col de Porte, even if the maximum snow depth is enough to bury the poles, for most of the winter the poles will be exposed to some degree. To avoid the poles influencing the meltwater flow as much as possible, instead of mounting electrodes on poles one above another, poles of varying heights could be installed, with one electrode at the top of each pole. This would be similar to snow temperature sensors used in Switzerland as part of the IMIS network (Lehning and others, 1999). Although similar preferential flow and melt problems would undoubtedly be experienced to a degree, this style of installation could mean that the snow above the electrodes remained undisturbed.

To reduce noise, siting the array in a more electrically quiet location would go some way to helping this, but in reality this may not be practical. Sites with the requisite infrastructure and power availability are likely to be electrically noisy environments. To mitigate this as much as possible, future installations should include steps to quantify the noise present, so that some of it can be subtracted from the signal. Improving electrode siting may also help reduce noise, as noise is likely to be less of an issue if electrical contact is better.

Although the remotely programmable logger set up was useful, the hard-wired multiplexer layout was a constraint. In future, a more flexible arrangement would allow for different combinations of dipoles to be measured, and easier identification of problem electrode pairs.

The difference in noise levels between the Petiau electrodes in the soil, and the lead strip electrodes on the poles was significant. Manufacturing smaller bespoke Petiau-style lead/lead chloride electrodes for mounting as the pole electrodes was considered, as in the laboratory experiments in Kulessa and others (2012), but it was decided that this type of electrode would not be reliable if exposed to the open air and repeated freezing and thawing cycles. It is possible that a better design using lead, or medical grade electroencephalogram materials would be possible, however the issue of electrical contact will always be an issue with electrodes that are left in situ for long periods. Siting one electrode at the top of each pole could address some of these problems as discussed above.

SP measurements could be combined with temperature measurements at each electrode using thermistors. This would enable verification of when liquid water flow is possible, improving interpretation of the SP signals. Future experiments could use lysimeters within the snowpack to better quantify how much flow is occurring and how this relates to the SP measurements, although this would be a destructive measurement and would not be suited to a monitoring campaign.

A key future direction of SP measurements in snow will be to compare modelled SP signals to those measured. Studies by Kulessa and others (2012), Thompson and others (2016) and Clayton (2021) have proven the utility of using electrical models to use SP signals to infer snow hydrological properties in the laboratory and in the field. This feasibility study has shown that longer-term in situ monitoring of SP can work. State of the art energy-balance snow physics models can predict internal water fluxes in snow, but are very difficult to verify with measurements. Ongoing research is looking to couple electrical models of snow to energy-balance snow physics models. By comparing predicted SP signals to those measured through the snowpack during melting or rain-on-snow events, it may be possible to improve the way that models simulate internal water flux, and thus improve the overall performance of snowmelt runoff predictions, with obvious advantages for those reliant on snowmelt runoff forecasts for assessing flood and avalanche risk.

\section{Conclusions}

In this study, a preliminary installation of an SP monitoring array for seasonal snow was introduced. Some data from a field season at Col de Porte in the French Alps were discussed. These data showed the SP method's utility as a sensor for internal water flow in snow, using simple, low-cost equipment. The system was able to detect meltwater flow in response to diurnal melt cycles, and successfully detected rainwater percolation during rain-on-snow events. Although the data were noisy and limited in the number of electrodes able to provide useful data due to snow depth, the system has shown the potential of SP measurements in future snow science research. The system's ability to detect water flow within the snowpack before it was registered in conventional lysimeters shows the most promise for future development. By coupling an SP system to a high-resolution snow physics model, it may be possible to improve our ability to model the timing of meltwater fluxes through seasonal 
snowpacks. It is important to consider that, like all geophysical methods, SP measurements should not be considered a stand-alone tool. This method has been shown to have potential to improve our understanding of liquid water dynamics in snow when used in conjunction with a wide range of other measurement techniques. Combining SP measurements with models could show the most promise for improving our ability to predict snowmelt runoff timing, and thus give wide and significant benefits to those who rely on seasonal snow for their water supply, or are at risk of hazards associated with it.

Acknowledgements. This research was carried out as part of a NERC E3 Doctoral Training Partnership studentship under grant NE/L002558/1, in partnership with British Geological Survey who provided additional CASE funding. The authors thank the staff at the Centre d'Etude de la Neige for their invaluable contribution to the success of this study, especially Mathieu Fructus and Marie Dumont. Colin Kay and Alan Hobbs at the NERC Geophysical Equipment Facility gave excellent advice and manufacturing expertise.

\section{References}

Avanzi F, Hirashima H, Yamaguchi S, Katsushima T and De Michele C (2016) Observations of capillary barriers and preferential flow in layered snow during cold laboratory experiments. The Cryosphere 10(5), 20132026. doi: 10.5194/tc-10-2013-2016

Barnett TP, Adam JC and Lettenmaier DP (2005) Potential impacts of a warming climate on water availability in snow-dominated regions. Nature 438(2), 303-309. doi: 10.1038/nature04141

Campbell FM, Nienow PW and Purves RS (2006) Role of the supraglacial snowpack in mediating meltwater delivery to the glacier system as inferred from dye tracer investigations. Hydrological Processes 20(4), 969-985. doi: 10.1002/hyp.6115

Chave AD, Jones AG, Mackie R and Rodi W (2012) The Magnetotelluric Method. Cambridge University Press, Cambridge.

Clayton WS (2021) Measurement of unsaturated meltwater percolation flux in seasonal snowpack using self-potential. Journal of Glaciology 1-16. doi: 10.1017/jog.2021.67

Colangelo G, Lapenna V, Perrone A, Piscitelli S and Telesca L (2006) 2D self-potential tomographies for studying groundwater flows in the Varco d'Izzo landslide (Basilicata, southern Italy). Engineering Geology 88(3-4), 274-286. doi: 10.1016/j.enggeo.2006.09.014

Colbeck SC (1975) A theory for water flow through a layered snowpack. Water Resources Research 11(2), 261-266.

Corry CE, Demoully GT and Gerety MT (1983) Field Procedure Manual for Self-Potential Surveys. Technical report, Zonge Engineering \& Research Organization, Tucson, Arizona.

Denoth A (1994) An electronic device for long-term snow wetness recording. Annals of Glaciology 19, 104-106.

Di Maio R and 6 others (1997) Self-potential, geoelectric and magnetotelluric studies in Italian active volcanic areas. Annali di Geofisica 40(2), 519-537. doi: 10.4401/ag-3926

Doherty R and 5 others (2010) A microbial fuel cell in contaminated ground delineated by electrical self-potential and normalized induced polarization data. Journal of Geophysical Research: Biogeosciences 115(G3), 1-11. doi: 10.1029/2009JG001131

Dong C (2018) Remote sensing, hydrological modeling and in situ observations in snow cover research: a review. Journal of Hydrology 561, 573583. doi: 10.1016/j.jhydrol.2018.04.027

Egbert GD and Booker JR (1992) Very long period magnetotellurics at Tucson observatory: implications for mantle conductivity. Journal of Geophysical Research 97(B11), 15113-15218. doi: 10.1029/92jb01251

Eiriksson D and 8 others (2013) An evaluation of the hydrologic relevance of lateral flow in snow at hillslope and catchment scales. Hydrological Processes 27(5), 640-654. doi: 10.1002/hyp.9666

Essery R (2015) A factorial snowpack model (FSM 1.0). Geoscientific Model Development 8(12), 3867-3876. doi: 10.5194/gmd-8-3867-2015

Essery R and Etchevers P (2004) Parameter sensitivity in simulations of snowmelt. Journal of Geophysical Research D: Atmospheres 109(20), 1-15. doi: 10.1029/2004JD005036
Essery R, Morin S, Lejeune Y and B Ménard C (2013) A comparison of 1701 snow models using observations from an alpine site. Advances in Water Resources 55, 131-148. doi: 10.1016/j.advwatres.2012.07.013

Fierz C and 8 others (2009) The international classification for seasonal snow on the ground. IHP-VII Technical Documents in Hydrology 83(1), 90. http:// www.cosis.net/abstracts/EGU05/09775/EGU05-J-09775.pdf

Friedel S, Byrdina S, Jacobs F and Zimmer M (2004) Self-potential and ground temperature at Merapi volcano prior to its crisis in the rainy season of 2000-2001. Journal of Volcanology and Geothermal Research 134(3), 149-168. doi: 10.1016/j.jvolgeores.2004.01.006

Gibert D, Le Mouël JL, Lambs L, Nicollin F and Perrier F (2006) Sap flow and daily electric potential variations in a tree trunk. Plant Science 171(5), 572-584. doi: 10.1016/j.plantsci.2006.06.012

Heilig A and 6 others (2015) Seasonal and diurnal cycles of liquid water in snow - measurements and modeling. Journal of Geophysical Research: Earth Surface 120(10), 2139-2154. doi: 10.1002/2015JF003593

Heilig A, Eisen O, MacFerrin M, Tedesco M and Fettweis X (2018) Seasonal monitoring of melt and accumulation within the deep percolation zone of the Greenland ice sheet and comparison with simulations of regional climate modeling. The Cryosphere 12(6), 1851-1866. doi: 10.5194/tc-121851-2018

Hu K, Jougnot D, Huang Q, Looms MC and Linde N (2020) Advancing quantitative understanding of self-potential signatures in the critical zone through long-term monitoring. Journal of Hydrology 585(2), 124771. doi: $10.1016 /$ j.jhydrol.2020.124771

Humphrey NF, Harper JT and Pfeffer WT (2012) Thermal tracking of meltwater retention in Greenland's accumulation area. Journal of Geophysical Research: Earth Surface 117(F1). doi: 10.1029/2011JF002083

Jardani A, Dupont JP and Revil A (2006) Self-potential signals associated with preferential groundwater flow pathways in sinkholes. Journal of Geophysical Research: Solid Earth 111(9), 1-13. doi: 10.1029/2005JB004231

Kallay N, Čop A, Chibowski E and Holysz L (2003) Reversible charging of the ice-water interface: II. Estimation of equilibrium parameters. Journal of Colloid and Interface Science 259(1), 89-96. doi: 10.1016/S0021-9797 (02)00179-0

Kattelmann R (2000) Snowmelt lysimeters in the evaluation of snowmelt models. Annals of Glaciology 31, 405-410. doi: 10.3189/172756400781820048

Kinar NJ and Pomeroy JW (2015) Measurement of the physical properties of the snowpack. Reviews of Geophysics 53, 481-544. doi: 10.1002/2015RG000481. Received

Koch F and 8 others (2019) Retrieval of snow water equivalent, liquid water content, and snow height of dry and wet snow by combining GPS signal attenuation and time delay. Water Resources Research 55(5), 4465-4487. doi: 10.1029/2018WR024431

Koch F, Prasch M, Schmid L, Schweizer J and Mauser W (2014) Measuring snow liquid water content with low-cost GPS receivers. Sensors (Switzerland) 14(11), 20975-20999. doi: 10.3390/s141120975

Kulessa B (2003) Cross-coupled flow modeling of coincident streaming and electrochemical potentials and application to subglacial self-potential data. Journal of Geophysical Research 108(B8), 2381. doi: 10.1029/ 2001JB001167

Kulessa B, Chandler D, Revil A and Essery R (2012) Theory and numerical modeling of electrical self-potential signatures of unsaturated flow in melting snow. Water Resources Research 48(2), 1-18. doi: 10.1029/ 2012WR012048

Largeron C and 9 others (2020) Toward snow cover estimation in mountainous areas using modern data assimilation methods: a review. Frontiers in Earth Science 8, 325. doi: 10.3389/feart.2020.00325

Lehning $\mathbf{M}$ and 5 others (1999) SNOWPACK model calculations for avalanche warning based upon a new network of weather and snow stations. Cold Regions Science and Technology 30(1-3), 145-157. doi: 10.1016/ S0165-232X(99)00022-1

Lehning M (2009) R.L. Armstrong and E. Brun, eds. 2008. Snow and climate: physical processes, surface energy exchange and modelling. Cambridge University Press, Cambridge. 256pp. ISBN-10: 0-521854-54-7, ISBN-13: 978-0-52185-454-7. Journal of Glaciology, 55(190), 384-384. doi: 10.3189/ 002214309788608741

Lejeune Y and 7 others (2019) 57 years (1960-2017) of snow and meteorological observations from a mid-altitude mountain site (Col de Porte, France, $1325 \mathrm{~m}$ of altitude). Earth System Science Data 11(1), 71-88. doi: 10.5194/essd-11-71-2019 
MacAllister DJ, Jackson MD, Butler AP and Vinogradov J (2016) Tidal influence on self-potential measurements. Journal of Geophysical Research: Solid Earth 121(12), 8432-8452. doi: 10.1002/2016JB013376

Magnusson J and 5 others (2015) Evaluating snow models with varying process representations for hydrological applications. Water Resources Research 51(4), 2707-2723. doi: 10.1002/2014WR016498

Marchenko SA, van Pelt WJJ, Pettersson R, Pohjola VA and Reijmer CH (2021) Water content of firn at Lomonosovfonna, Svalbard, derived from subsurface temperature measurements. Journal of Glaciology 67, 1-12. doi: $10.1017 /$ jog.2021.43

Marsh P (1985) Meltwater movement in natural heterogeneous snow covers. Water Resources Research 21(11), 1710-1716.

Mitterer C, Heilig A, Schweizer J and Eisen O (2011) Upward-looking ground-penetrating radar for measuring wet-snow properties. Cold Regions Science and Technology 69(2-3), 129-138. doi: 10.1016/j.coldregions.2011.06.003

Moore JR, Boleve A, Sanders JW and Glaser SD (2011) Self-potential investigation of moraine dam seepage. Journal of Applied Geophysics 74(4), 277 286. doi: $10.1016 /$ j.jappgeo.2011.06.014

Morin S and 6 others (2012) A 18-yr long (1993-2011) snow and meteorological dataset from a mid-altitude mountain site (Col de Porte, France, $1325 \mathrm{~m}$ alt.) for driving and evaluating snowpack models. Earth System Science Data Discussions 5(1), 29-45. doi: 10.5194/essdd-5-29-2012

Peitzsch E, Birkeland KW and Hansen KJ (2008) Water movement and capillary barriers in a stratified and inclined snowpack. In International Snow Science Workshop.

Pérez Díaz CL, Muñoz J, Lakhankar T, Khanbilvardi $\mathbf{R}$ and Romanov $\mathbf{P}$ (2017) Proof of concept: Development of snow liquid water content profiler using CS650 reflectometers at Caribou, ME, USA. Sensors (Switzerland) 17(3), Article no 647. doi: 10.3390/s17030647

Petiau G (2000) Second generation of lead-lead chloride electrodes for geophysical applications. Pure and Applied Geophysics 157(3), 357-382. doi: $10.1007 / \mathrm{s} 000240050004$

Pfeffer WT and Humphrey NF (1996) Determination of timing and location of water movement and ice-layer formation by temperature measurements in sub-freezing snow. Journal of Glaciology 42(141), 292-304. doi: 10.3189/ S0022143000004159

Revil A and 5 others 2010) Understanding biogeobatteries: where geophysics meets microbiology. Journal of Geophysical Research: Biogeosciences 115 (G1), 1-22. doi: 10.1029/2009JG001065

Revil A, Ahmed AS and Jardani A (2017) Self-potential: a non-intrusive ground water flow sensor. Journal of Environmental and Engineering Geophysics 22(3), 235-247. doi: 10.2113/JEEG22.3.235

Revil A, Naudet V, Nouzaret J and Pessel M (2003) Principles of electrography applied to self-potential electrokinetic sources and hydrogeological applications. Water Resources Research 39(5), 1-15. doi: 10.1029/ 2001WR000916
Schmid L and 6 others (2014) Continuous snowpack monitoring using upward-looking ground-penetrating radar technology. Journal of Glaciology 60(221), 509-525. doi: 10.3189/2014JoG13J084

Schneebeli M (1995) Development and stability of preferential flow paths in a layered snowpack. Biogeochemistry of Seasonally Snow Covered Basins 228, 89-96.

Sill WR (1983) Self-potential modeling from primary flows. Geophysics 48(1), 76-86. doi: 10.1190/1.1441409

Stein J (1997) Monitoring the dry density and the liquid water content of snow using time domain reflectometry (TDR). Cold Regions Science and Technology 25, 123-136.

Sundström N, Gustafsson D, Kruglyak A and Lundberg A (2012) Field evaluation of a new method for estimation of liquid water content and snow water equivalent of wet snowpacks with GPR. Hydrology Research 44(4), 600-613. doi: 10.2166/nh.2012.182

Thompson SS, Kulessa B, Essery RL and Lüthi MP (2016) Bulk meltwater flow and liquid water content of snowpacks mapped using the electrical selfpotential (SP) method. The Cryosphere 10(1), 433-444. doi: 10.5194/ tc-10-433-2016

Thompson S, Kulessa B and Luckman A (2012) Integrated electrical resistivity tomography (ERT) and self-potential (SP) techniques for assessing hydrological processes within glacial lake moraine dams. Journal of Glaciology 58(211), 849-858. doi: 10.3189/2012JoG11J235

Tiuri M, Sihvola A, Nyfors E and Hallikaiken M (1984) The complex dielectric constant of snow at microwave frequencies. The IEEE Journal of Oceanic Engineering 9(5), 377-382. doi: 10.1109/JOE.1984.1145645

Tsai YLS, Dietz A, Oppelt N and Kuenzer C (2019) Remote sensing of snow cover using spaceborne SAR: a review. Remote Sensing 11(12), 1456. doi: $10.3390 / \mathrm{rs} 11121456$

Voytek EB, Barnard HR, Jougnot D and Singha K (2019) Transpiration- and precipitation-induced subsurface water flow observed using the selfpotential method. Hydrological Processes 33(13), 1784-1801. doi: 10.1002/ hyp. 13453

Weigand $\mathbf{M}$ and 5 others (2020) A monitoring system for spatiotemporal electrical self-potential measurements in cryospheric environments. Geoscientific Instrumentation, Methods and Data Systems 9(2), 317-336. doi: 10.5194/gi-9-317-2020

Wever N, Fierz C, Mitterer C, Hirashima H and Lehning M (2014) Solving Richards equation for snow improves snowpack meltwater runoff estimations in detailed multi-layer snowpack model. The Cryosphere 8(1), 257-274. doi: 10.5194/tc-8-257-2014

Wilkinson PB and 5 others (2005) A comparison of self-potential tomography with electrical resistivity tomography for the detection of abandoned mineshafts. Journal of engineering and environmental geophysics 10(4), 381-389.

Williams MW, Erickson TA and Petrzelka JL (2010) Visualizing meltwater flow through snow at the centimetre-to-metre scale using a snow guillotine. Hydrological Processes 24(15), 2098-2110. doi: 10.1002/hyp.7630 